\title{
Análise da influência do diâmetro no rendimento em madeira serrada de cambará
}

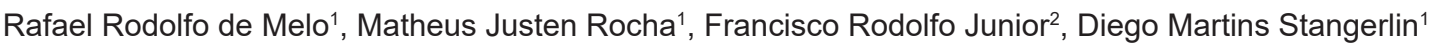 \\ 'Universidade Federal do Mato Grosso, Av. Alexandre Ferronato, 1200, St. Industrial, SCEP 78.557-267, Sinop, MT, Brasil \\ ${ }^{2}$ Universidade Federal do Piauí, Rod. BR, 135, Bairro Planalto Horizonte, CEP 64900-000, Bom Jesus, PI, Brasil
}

"Autor correspondente:
rrmelo2@yahoo.com.br

Termos para indexação:

Madeiras da Amazônia

Rentabilidade

Serraria

Index terms:

Amazon wood

Wood sawing

Sawmill

Histórico do artigo:

Recebido em 13/02/2016

Aprovado em 05/09/2016

Publicado em 30/12/2016

doi: $10.4336 / 2016 . p f b .36 .88 .1151$

\begin{abstract}
Resumo - Este trabalho teve como objetivo determinar e avaliar o rendimento de madeira serrada de cambará (Qualea sp.) em diferentes classes de diâmetro. O estudo foi realizado em uma serraria localizada na região Norte do Estado de Mato Grosso, onde foram selecionadas sessenta toras, aleatoriamente, e agrupadas em quatro classes de quinze toras cada. As classes avaliadas foram: diâmetros inferiores a $55 \mathrm{~cm}$ (classe I); entre 55 e $65 \mathrm{~cm}$ (classe II), entre 65 e $75 \mathrm{~cm}$ (classe III) e diâmetros superiores a 75 cm (classe IV). Em média, observou-se cerca de 52\% de rendimento para o cambará. Observou-se ainda que a classe diamétrica influenciou significativamente o rendimento do cambará, sendo a classe IV a que proporcionou maior rendimento. Entretanto, não se verificou tendência linear significativa para a relação entre estas variáveis e sim um comportamento parabólico, com os maiores percentuais de aproveitamento da madeira observados para a maior e menor classe avaliadas.
\end{abstract}

\section{Influence of diameter class on lumber yielding of Qualea sp.}

\section{Introdução}

Dados da Food and Agriculture Organization (FAO, 2015) apontam o Brasil como o maior produtor de madeira tropical do mundo, respondendo aproximadamente por dois terços do volume de madeira tropical produzido na América. De acordo com Biasi \& Rocha (2007), o país se destaca como um dos principais consumidores dessa matéria-prima, utilizando a maior parte do que é produzido. Os mesmos autores mencionam ainda que a região Amazônica é uma das maiores reservas de madeira tropical, tendo um papel fundamental como fornecedora de madeiras para os mercados nacional e internacional.

Na Amazônia Legal brasileira, o Estado de Mato Grosso apresenta-se como um dos principais produtores de madeira. A região Norte do Estado, recoberta pela Floresta Amazônica, possui um elevado volume e diversidade de madeiras de importância comercial 
como cambará (Qualea paraensis), cedro (Cedrela sp.) garapeira (Apuleia leiocarpa), itaúba (Mezilaurus itauba), amescla (Trattinickia burseraefolia), angelim (Hymenolobium modestum), dentre outras (Angelo et al., 2004; Melo et al., 2015). O setor florestal é uma das principais fontes de receita do Estado e contabilizou em 2014 um total de 228 planos de manejos (PMFS) aprovados, totalizando uma área de $243.925,58$ ha, onde foram movimentados cerca de US\$ 86 milhões com a venda para o mercado internacional e $\mathrm{R} \$ 39$ milhões para mercado interno, segundo artigo publicado na página do Centro das Indústrias Produtoras e Exportadoras de Madeirado no Estado de Mato Grosso (CIPEM) (Bento, 2015). Apesar de este potencial madeireiro trazer muitos benefícios para a região, problemas tecnológicos ou de pouco conhecimento sobre a matéria-prima são considerados algumas das principais deficiências do setor, o que resulta em um baixo aproveitamento, aumento do custo do produto final e a produção de um grande volume de resíduos (Rocha, 2007).

A intensa utilização da madeira e derivados tem motivado políticas conservacionistas, que visam o uso consciente de um bem tão abundante no país. Com base nessas políticas, torna-se essencial aumentar as pesquisas de métodos de desdobro e tecnologias para aperfeiçoar a produção madeireira. O sucesso de um empreendimento madeireiro está diretamente ligado à variável rendimento, que por sua vez está interligada a diversos fatores, como disponibilidade de recursos, mão de obra qualificada e gastos com transportes. São esses os principais fatores que, muitas vezes, inviabilizam a exploração da madeira no Brasil (Rocha, 2007; Vital, 2008).

Na Região Norte do Estado de Mato Grosso ainda é significativo o uso do modo convencional de transformação da matéria-prima, onde as toras são desdobradas sem classificação e sem uma definição exata de um modelo de corte, pois o operador é quem determina a maneira como o corte será conduzido. Este procedimento, muitas vezes, induz a um baixo aproveitamento da tora, gerando um volume maior de subprodutos, que, consequentemente, acarreta aumento nos preços do produto final. Deste modo, o presente trabalho teve como objetivo avaliar o rendimento em madeira serrada do cambará (Qualea sp.) em uma serraria no Norte de Mato Grosso, visando subsidiar a otimização do desdobro de espécies com importância econômica para a região.

\section{Material e métodos}

\section{Descrição da serraria}

O trabalho foi realizado em uma serraria localizada na cidade de Sorriso, MT, situada na Região Norte do Mato Grosso, às margens da BR-163. A serraria avaliada apresentava uma capacidade média de produção de 250 a $350 \mathrm{~m}^{3}$ mês $^{-1}$, produzindo madeira serrada (pranchas, tábuas, ripas, caibros e vigas) e madeira beneficiada (forros e decks). A principal espécie desdobrada na serraria é cambará (Qualea sp.), assim como em toda a região em que foi realizado o presente estudo.

O desdobro primário (principal) das toras foi realizado com serra fita horizontal industrial, com diâmetro de volantes $1,10 \mathrm{~m}$ e potência de $75 \mathrm{CV}$; o refilo das peças foi feito com serra circular de mesa, com $30 \mathrm{~cm}$ de diâmetro e $20 \mathrm{CV}$ de potência (cateadeira); e o destopo e aproveitamento de peças com defeitos foi realizado com uma serra destopadeira pendular, com discos de $25 \mathrm{~cm}$ de diâmetros e $10 \mathrm{CV}$ de potência. Estes equipamentos compõem um layout padrão, frequentemente observado na maioria das empresas da região.

\section{Seleção das toras}

No pátio da serraria foram selecionadas aleatoriamente 60 toras, sendo estas subdivididas em quatro classes de diâmetro, conforme apresentado na Tabela 1. Para determinação do diâmetro de cada tora foram tomadas duas medidas de diâmetro perpendiculares em cada uma das extremidades, sendo, em seguida, calculada a média aritmética destes valores.

Tabela 1. Classes diamétricas avaliadas para a madeira de cambará (Qualea sp.), em Sorriso, MT.

\begin{tabular}{cccc}
\hline $\begin{array}{c}\text { Classe } \\
\text { Diamétrica }\end{array}$ & $\begin{array}{c}\text { Diâmetro } \\
\text { médio }(\mathbf{c m})\end{array}$ & $\begin{array}{c}\text { Número de } \\
\text { toras }\end{array}$ & $\begin{array}{c}\text { Comprimento } \\
\text { médio }(\mathbf{m})\end{array}$ \\
Classe I & $<55$ & 15 & 5,08 \\
Classe II & $55-65$ & 15 & 4,67 \\
Classe III & $65-75$ & 15 & 4,84 \\
Classe IV & $>75$ & 15 & 4,80 \\
\hline
\end{tabular}

\section{Desdobro das toras}

O desdobro das toras foi realizado conforme metodologia adotada por Biasi \& Rocha (2007). O comprimento das toras avaliadas variou entre $4,00 \mathrm{~m} \mathrm{e}$ $6,00 \mathrm{~m}$. Em seguida, as toras foram submetidas à serra fita, para retiradas das costaneiras e da primeira tábua. $\mathrm{Na}$ sequência, foi feito um giro na tora para retirada de mais uma costaneira e da primeira tábua, formando 
um semibloco. O semibloco foi, então, desdobrado por meio de cortes sucessivos, originando tábuas, as quais seguiram para a serra circular canteadeira, para ajuste das larguras. Por fim, realizou-se, quando necessário, o destopo das tábuas que apresentavam defeitos, como rachaduras, apodrecimentos e outros.

\section{Volume das toras e rendimento em madeira serrada}

$\mathrm{O}$ volume de cada tora foi determinado utilizando-se as medidas de diâmetro com casca e comprimento de cada tora (Equação 1). O rendimento em madeira serrada foi obtido pela razão entre o volume em madeira serrada produzido por cada tora e o volume da respectiva tora, multiplicado por 100 .

$$
V_{T}=\frac{\pi \times D^{2}}{40000} \times L
$$

Em que: $V_{T}=$ volume da tora $\left(\mathrm{m}^{3}\right) ; D=$ diâmetro médio da tora com casca $(\mathrm{cm}) ; L=$ comprimento da tora $(\mathrm{m})$.

\section{Volume de resíduos}

Os resíduos gerados foram classificados em: serragem da serra fita; serragem das serras circulares; casca; e resíduos sólidos de costaneiras e destopos (denominados outros). O volume de resíduo gerado pelo processamento da serra fita foi determinado por meio da cubagem do volume de serragem produzido. A mesma técnica foi utilizada para estimar o resíduo produzido pelas serras circulares. Para ambos os casos, considerou-se a amostragem de cinco toras para cada classe de diâmetro.

A perda com casca foi estimada utilizando a Equação 2 e a determinação do volume dos resíduos sólidos de costaneiras e destopos, foi estimado pela diferença entre o volume total de cada tora e os volumes de madeira, casca e serragem (Equação 3). Posteriormente, todos estes valores foram transformados em percentuais.

$$
V_{C}=V_{T}-\left(\frac{\pi \times D s c^{2}}{40.000} \times L\right)
$$

Em que: $V_{C}=$ volume das costaneiras e destopos $\left(\mathrm{m}^{3}\right)$; $V_{T}=$ volume da tora $\left(\mathrm{m}^{3}\right) D_{S C}=$ diâmetro médio da tora sem casca $(\mathrm{cm}) ; L=$ comprimento da tora $(\mathrm{m})$.

$$
V_{R}=V_{T}^{-}\left(V_{M}+V_{C}+V_{S}\right)
$$

Em que: $V_{R,} V_{T} V_{M}, V_{C}$ e $V_{S}$ são, respectivamente, volume $\left(\mathrm{m}^{3}\right)$ de outros resíduos, da tora com casca, de madeira serrada, da casca e da serragem.

\section{Análise dos resultados}

Realizou-se análise de variância (ANOVA) para verificar a possível diferença entre as classes diamétricas avaliadas, utilizando-se nível de significância de 5\% para o teste F. Para os parâmetros nos quais foi detectada variação significativa pelo teste $F$, os dados foram comparados pelo teste de Tukey $(\mathrm{p}<0,05)$. Foi realizada ainda análise de regressão para avaliar a eficiência da utilização do diâmetro como variável para estimativa do rendimento em madeira serrada.

\section{Resultados e discussão}

O rendimento médio em madeira serrada e as perdas do processo de desdobro estão demonstrados na Figura 1. O rendimento médio observado para madeira de cambará (Qualea sp.) foi de 52,18\%. Tais resultados estão dentro do percentual considerado normal para o rendimento de madeiras tropicais, conforme sugerido por Rocha (2007) e Vital (2008), que apontam para estes casos, percentuais variando entre $45 \%$ e $55 \%$.

Garcia (2013) observou valores semelhantes ao do presente estudo. Ao analisar o desempenho de uma serraria na Região Norte do Estado de Mato Grosso, o autor observou um rendimento médio em madeira serrada de 48,90\% para madeira de Qualea albiflora. Em serrarias da mesma Região, Garcia et al. (2012) também verificaram rendimentos similares para as madeiras de itaúba (Mezilaurus itauba) e tauari (Couratari guianensis), com valores médios de $49,64 \%$ e 46,39\%, respectivamente. Entretanto, estes valores são inferiores aos observados por Biasi \& Rocha (2007) e Botin (2011) que verificaram, para a mesma espécie, rendimento médio de $59,83 \%$ e $60,49 \%$, respectivamente.

A transformação de toras em tábuas, pranchas, vigas ou outras peças de madeira implica em diferentes quantidades de perdas, podendo variar de acordo com os fatores que influem no seu volume, sejam eles: a natureza da matéria-prima, a eficiência das máquinas empregadas pela indústria e as exigências do mercado. No presente estudo, observou-se uma elevada porcentagem média de perdas com resíduos $(47,82 \%)$, o que pode acarretar elevação de custo, pois quase a metade da matéria prima não será transformada em madeira serrada. Outro parâmetro relevante a considerar no rendimento em madeira serrada trata-se da relação cerne-alburno, que 
pode variar entre os indivíduos avaliados, mesmo que estes sejam de uma mesma espécie. Na maioria dos casos, apenas o cerne é aproveitado, sendo o alburno caracterizado como resíduo, ou é usado para gerar produtos de menor valor agregado, com a produção de peças com dimensões reduzidas.

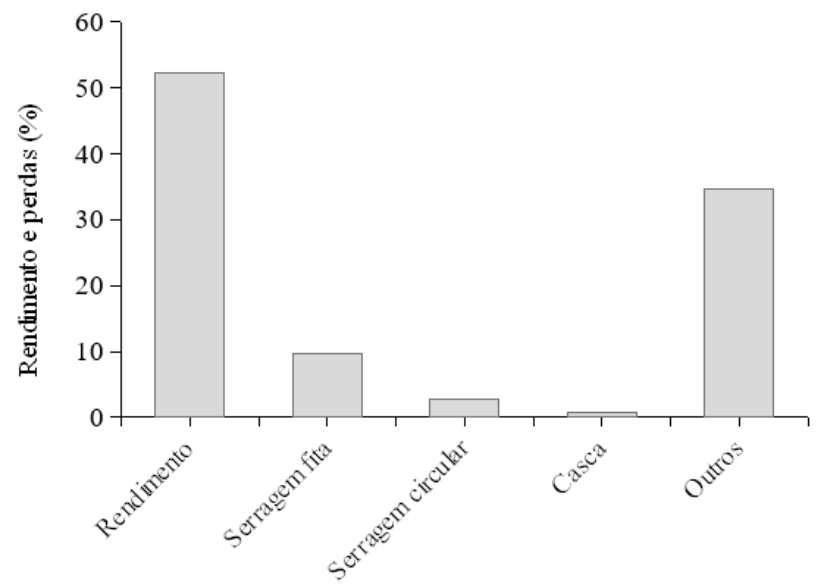

Figura 1. Percentuais de rendimento em madeira serrada e perdas no processo de desdobro de Qualea sp.

As maiores perdas observadas no processamento (Figura 1) ocorreram em virtude do mau aproveitamento das peças ou qualidade baixa das toras, acarretando descarte de refilos e costaneiras, representando, aproximadamente, $35,54 \%$ das toras. A segunda maior perda foi resultado do processo de serragem. $\mathrm{O}$ processamento das toras em madeira serrada acarreta perdas que atingem valores superiores a $12 \%$, sendo quase $10 \%$ referente a serragem originada do desdobro primário (serra-fita) e cerca de $3 \%$ resultantes das operações de desdobro e refilo (serra-circular). Biasi \& Rocha (2007) observaram para resíduos gerados no desdobro do cambará os valores de 7,22\% (serragem serra-fita), 2,98 (serragem serra-circular) e $27,16 \%$ (outros resíduos).

As perdas com casca para o cambará chegaram a quase $1 \%$, valores que podem ser considerados baixos, o que na prática implica em diversos benefícios para o processo de beneficiamento desta espécie. De acordo com Miranda et al. (2002), a casca, quando presente na madeira, pode representar problemas econômicos aos empreendimentos florestais, uma vez que seu volume implica em custos de colheita e transporte, descascamento, acúmulo de resíduo, entre outros.

Garcia et al. (2012) destacam que as perdas ocasionadas durante o processo de desdobro (costaneiras, pó de serra, ponta de peças, casca, etc.) nas serrarias da região Amazônica acarretam desperdício de matériaprima, podendo chega a um volume de perdas superior ao volume de madeira serrada que pode ser aproveitado. Para Brand et al. (2001), isso faz com que para incrementar sua produção, estas empresas necessitem aumentar o volume de matéria-prima o que, consequentemente, resulta em geração maior de resíduos que, frequentemente não apresentam utilização direta na indústria em que foram gerados. $\mathrm{O}$ baixo rendimento e elevado volume de resíduos gerados no desdobro de madeiras provenientes de florestas tropicais também têm sido reportado em outros países, a exemplo da Nigéria (Ojo \& Obalokun, 2005), Malásia (Sim, 1989), Indonésia e Filipinas (Elvin et al., 1993).

Foi observada influência das classes diamétricas no rendimento em madeira serrada (Figura 2a). Garcia (2013), ao estudar rendimento em madeira serrada de cambará, também observou que as características dendrométricas das toras influenciam no processo de desdobro e no rendimento final, sendo esses fatores também observados por outros autores (Egas, 2000; Murara Junior et al., 2005; Biasi \& Rocha, 2007; Rocha, 2007; Vital, 2008; Valério, 2007, 2009; Manhiça et al., 2013).

Os resultados observados para as diferentes classes diamétricas avaliadas indicam que os maiores percentuais foram observados para as classes de menor e maior diâmetro. Tais resultados diferem dos sugeridos por Ribas et al. (1989) e Tsoumis (1991), que mencionam haver uma relação direta entre o diâmetro e o rendimento das toras. Todavia, resultados similares foram observados por Biasi \& Rocha (2007) ao verificarem para três espécies tropicais, incluindo o cambará, que o diâmetro não influenciou significativamente o rendimento em madeira serrada. Sim (1989), ao estudar o rendimento da madeira Hevea brasiliensis, também não verificou um comportamento de incremento linear entre diâmetro e o rendimento em madeira serrada. Apesar disso, o autor destaca que a variável diâmetro pode ser utilizada para a estimativa do rendimento de serrarias e que a divisão das toras nos pátios por classe de diâmetro é fundamental para auxiliar o planejamento e controle das operações de serração.

Rocha (2000) verificou para a madeira de Eucalyptus grandis um rendimento superior para as classes de menores diâmetros. Segundo Murara Junior et al. (2005), estes resultados podem ser explicados devido à pequena 
variedade de produtos obtidos das toras. Ao avaliarem o rendimento em madeira serrada do ipê (Handroanthus

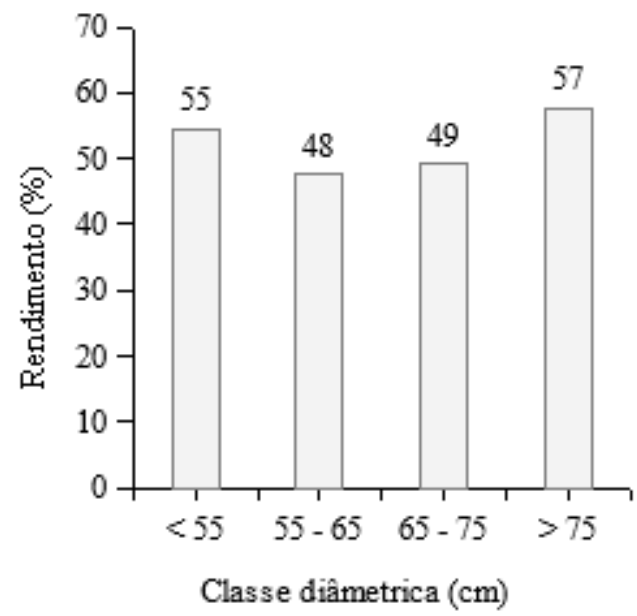

A sp.), Piovesan et al. (2013) também verificaram uma redução do rendimento com o aumento do diâmetro das toras.

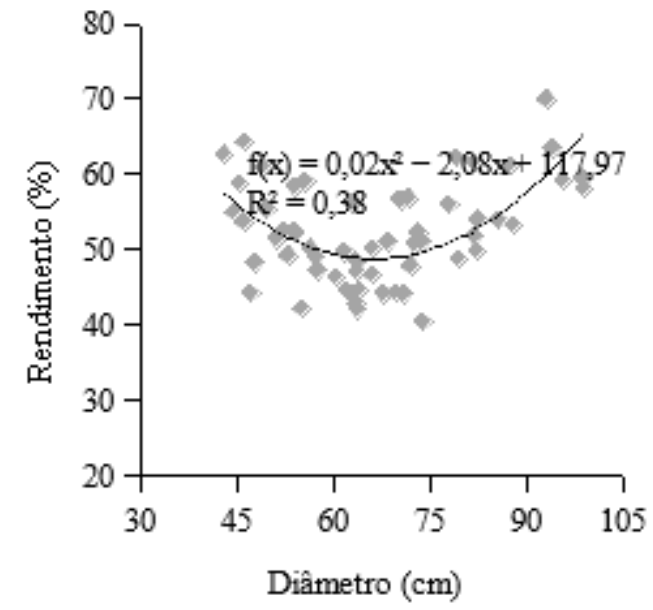

B

Figura 2. A. Percentuais de rendimento em madeira serrada de Qualea sp. para as diferentes classes diamétricas avaliadas e B. Análise de regressão avaliando a influência do diâmetro das toras no rendimento em madeira serrada de Qualea sp.

O rendimento em madeira serrada do cambará estimado utilizando-se como variável independente o diâmetro das toras está apresentado na Figura $2 b$. Esse resultado aponta para possibilidade do uso desta variável como base para estimativa de produção de uma serraria com base no seu estoque de madeira no pátio. A relação entre o rendimento em madeira serrada de cambará e o diâmetro médio da tora observado pela análise de regressão apresentou um comportamento parabólico, tendo os maiores valores sido observados para as classes de diâmetro menores e maiores. Este resultado difere dos observado por Murara Junior et al. (2005) e Juizo et al. (2015), que observaram uma relação linear e direta ao avaliarem a influência de diferentes classes diamétricas no rendimento em madeira serrada. Entretanto, Marchesan (2012) também observou redução do rendimento com o aumento do diâmetro, relatando que a presença dos defeitos é mais comum em toras com diâmetros acima de $50 \mathrm{~cm}$, em função da ocorrência de ocos causados por podridão e/ou ataque de organismos xilófagos, o que reduze o aproveitamento das peças.

O comportamento observado no presente estudo pode ser explicado pelas toras de menores diâmetros proporcionarem a obtenção de um número menor de peças e, consequentemente, menores perdas por serragem (devido à espessura de corte). Com o aumento do diâmetro, o número de produtos obtidos é maior, o que proporciona mais cortes e mais perdas por serragem. Todavia, com o aumento progressivo do diâmetro, a proporcionalidade destas perdas em relação ao volume total da tora é reduzida gradativamente. Esse comportamento pode ter ocasionado uma estabilização do rendimento na Classe III, seguida de um aumento significativo na última classe. Cabe ressaltar ainda, que fatores como a relação cerne/alburno, conicidade das toras, tipos de produtos, ocos e ataques de insetos também podem ter proporcionado esta variação.

\section{Conclusões}

O diâmetro das toras influencia significativamente o rendimento em madeira serrada de cambará (Qualea sp.), sendo os maiores rendimentos observados para toras com diâmetro superior a $75 \mathrm{~cm}$.

É possível estimar o volume de madeira serrada obtido por uma serraria a partir do diâmetro das toras disponíveis no pátio. 


\section{Referências}

Angelo, H. et al. Análise econômica da indústria de madeiras tropicais: o caso do polo de Sinop, MT. Ciência Florestal, v. 14, n. 2, p. 91-101, 2004. DOI: 10.5902/198050981809.

Bento, G. Base florestal de MT quer consolidar raízes e crescer ainda mais. Cuiabá: Cipem, [2015]. Disponível em: $<\mathrm{http}: / / \mathrm{www}$. cipem.org.br/conteudo.php?sid $=44 \&$ cid $=3081 \&$ parent $=0>$. Acesso em: 14 maio 2015.

Biasi, C. P. \& Rocha, M. P. Rendimento em madeira serrada e quantificação de resíduos para três espécies tropicais. Floresta, v. 37, n. 1, p. 95-108, 2007. DOI: 10.5380/rf.v37i1.7845

Botin, A. A. Influência das diferentes alturas de corte na qualidade produtividade e rendimento da madeira serrada de Qualea sp. na região norte do Estado de Mato Grosso. 2011. 61 f. Monografia (Graduação em Engenharia Florestal) - Universidade Federal de Mato Grosso, Sinop.

Brand, M. A. et al. Caracterização do rendimento e quantificação dos resíduos gerados em serraria gerado através do balanço de materiais. Floresta, v. 32, n. 2, p. 247-59, 2001. DOI: 10.5380/rf.v32i2.2288.

Egas, A. F. Noções sobre a produção de madeira serrada. Maputo: UEM, 2000. 98 p.

Elvin, C. T. et al. The forest products industry in Southeast Asia: An emphasis on Indonesia. Forest Products Journal, v. 43, n. 5, p. 15-44, 1993.

FAO. Faostat: forestry production and trade. Disponível em: $<$ http:// faostat3.fao.org/browse/F/FO/E>. Acesso em: 25 jun. 2015.

Garcia, F. M. et al. Rendimento no desdobro de toras de itaúba (Mezilaurus itauba) e tauarí (Couratari guianensis) segundo a classificação da qualidade da tora. Floresta e Ambiente, v. 19, p. 468-474, 2012. DOI: 10.4322/floram.2012.059.

Garcia, F. M. Rendimento operacional de uma serraria com a espécie cambará (Qualea albiflora Warm.) na região amazônica. 2013. 83f. Dissertação (Mestrado em Ciência Florestal) Universidade Estadual Paulista Júlio de Mesquita Filho, Botucatu.

Juizo, C. G. F. et al. Influência da classe diamétrica no rendimento em madeira serrada de duas espécies nativas de Moçambique. Pesquisa Florestal Brasileira, v. 35, n. 83, p. 293-298, 2015. DOI: 10.4336/2015.pfb.35.83.785.

Manhiça, A. A. et al. Eficiência operacional no desdobro de Pinus utilizando modelos de corte numa serraria de pequeno porte. Cerne, v.19, n. 2, p. 339-346, 2013. DOI: 10.1590/S010477602013000200019 .
Marchesan, R. Rendimento e qualidade de madeira serrada de três espécies tropicais. 2012. 92 f. Dissertação (Mestrado em Engenharia Florestal) - Universidade Federal do Paraná, Curitiba.

Melo, R. R. et al. Vouchers for releasing forestry credit (CLCF) for Sinop, Mato Grosso, Brazil. Nativa, v. 3, n. 1, p. 36-43, 2015. DOI: 10.14583/2318-7670.v03n01a06.

Miranda, G. M. et al. Contribuição da casca na composição do custo de transporte da madeira de eucalipto. Revista Árvore, v. 26, n. 2 , p.145-148, 2002.

Murara Junior, M. I. et al. Rendimento em madeira serrada de Pinus taeda para duas metodologias de desdobro. Floresta, v. 35, n. 3, p. 473-483, 2005. DOI: 10.5380/rf.v35i3.5186.

Ojo, O. \& Obalokun, B. M. Analyses of productivity and technical efficiency of sawmill industries in Nigeria. Journal of Tropical Forest Science, v. 17, n. 3, p. 428-437, 2005.

Piovesan, P. R. R. et al. Rendimento na produção de madeira serrada de ipê (Handroanthus sp). Enciclopédia Biosfera, v. 9, n. 17, p. 2315-2329, 2013.

Ribas C. et al. Estudo da influência do diâmetro e do comprimento das toras de Pinus elliottii na produção de madeira serrada e de resíduos de serraria. Revista do Instituto Florestal, v. 1, n. 1, p. 51-65, 1989.

Rocha, M. P. Eucalyptus grandis Hill ex Maiden e Eucalyptus dunnii Maiden como fontes de matéria-prima para serrarias. 2000. 185 f. Tese (Doutorado em Ciências Florestais) - Universidade Federal do Paraná, Curitiba.

Rocha, M. P. Técnicas de serrarias. In: Oliveira, J. T. S. et al. (Org.). Tecnologias aplicadas ao setor madeireiro. Jerônimo Monteiro: Suprema, 2007. p. 209-270.

Sim, H. C. Yields of rubberwood sawn timber. Journal of Tropical Forest Science, v. 2, n. 1, p. 48-55, 1989.

Tsoumis, G. Science and technology of wood: structure, properties, utilization. New York: Champman and Hall, 1991.

Valério, Á. F. et al. Modelagem para a estimativa do rendimento no desdobro de toras de Araucaria angustifolia (Bertol.) Kuntze. Floresta, v. 39, n. 3, 2009. DOI: 10.5380/rf.v39i3.15361.

Valério, A. F. et al. Quantificação de resíduos e rendimento no desdobro de Araucaria angustifolia (Bertol.) O. Kuntze. Floresta, v. 37, n. 3, 2007. DOI: 10.5380/rf.v37i3.9934.

Vital, B. R. Planejamento e operação de serrarias. Viçosa, MG: UFV, 2008. 211 p. 